\title{
Beyond the money: grantors supporting their grantees
}

\section{Giacomo Boesso $^{1}\left[\right.$ [ $\cdot$ Fabrizio Cerbioni ${ }^{1} \cdot$ Andrea Menini $^{1} \cdot$ Giulia Redigolo $^{2}$}

Accepted: 9 February 2022

(c) The Author(s) 2022

\begin{abstract}
This study analyses the relationship between grant-making foundations (grantors) and operative nonprofit organizations (grantees) to determine whether a positive association exists between foundations' intervention beyond the money and grantees' organizational capacity development. Data are collected using a survey of grantees who received funding from a Foundation of Banking Origin (FOB) in the context of Italy. The analyses portray three capacity-building factors that FOBs can deploy in addition to the financial grant, namely, operative support, goal alignment, and performance oversight. The results endorse our hypotheses that both the amount of operative support provided by the foundation and the higher perception of goal congruence between grantor and grantees are positively correlated with the organizational capacity of the grantee. Our results also suggest that the benefits of increased oversight prevail over the drawbacks.
\end{abstract}

Keywords Grant-making · Capacity-building · Strategic philanthropy

\section{Introduction}

Grant-making foundations (grantors) operate within what is called the third sector. The third sector is populated by nonprofit entities (grantees) that conduct projects targeted to a group of beneficiaries, such as the poor, the uneducated, or children. The money typically flows from grantors to grantees who actually implement the interventions. By definition, grantors' support is based on funding. However, it turns out that oftentimes grantees lack managerial and financial skills just as much as they need money (Ebarb, 2019). Hence, a grantor-grantee relation that goes beyond mere financing and includes knowledge transfer may be desirable whenever the grantor has the required skills.

Giacomo Boesso

giacomo.boesso@unipd.it

1 Department of Economics and Management, University of Padova, Padova, Italy

2 ESADE Ramon Llull University, Barcelona, Spain 
Academics and policymakers have been worried about how to increase the sustainability and reduce the risk of dissolution of nonprofit grantees (Lu et al., 2020). However, "there is little knowledge about what works and what doesn't that is based on, or even informed by, the perspectives of grantees [...] receiving assistance beyond the grant" (Centre for Effective Philanthropy [CEP], 2008, p. 3). This gap in the literature is attributed to several reasons. First, there are few studies that specifically evaluate the relation between grantors' non-financial support and grantees' performance (Fairfield \& Wing, 2008; MacIndoe \& Sullivan, 2014). This lack of evidence is undesirable: if effective, grantors' support could be a valuable and organizationally convenient source of managerial training for grantees, especially small ones (Ostrower, 2004). Second, the available evidence is mostly qualitative (Laurett \& Ferreira, 2018). This limitation clashes with the need of grantors called to invest in their relations with the grantees to have an informed expectation on how much more productive and sustainable their grantees will become thanks to their help. Moreover, quantitative studies are better equipped to deal with the selfselection that likely drives the spontaneous formation of successful grantor-grantee relations, which are the typical subjects of qualitative studies. Third, the grantors' perspective dominates the existing literature, whereas there is little evidence on the grantees' perception of grantors' non-financial support (Delfin \& Tang, 2008). Focusing exclusively on the grantors' standpoint is potentially misleading because grantor and grantee may have conflicting views (Fairfield \& Wing, 2008; Vangen \& Huxham, 2003), but it is the grantee who eventually manages the financial resources and determines the outcome of the financed project. Therefore, understanding grantees' needs should be a first-order concern.

In this research, we take a step toward filling these three gaps. We conduct an empirical analysis of the grantor-grantee relation on a novel dataset obtained from a sample of grantees of Italian Foundations of Banking Origin (FOBs). Specifically, we ask how operative support (Boesso \& Cerbioni, 2019; CEP, 2008), goal alignment (CEP, 2017; Leardini et al., 2019), and performance oversight (Despard, 2017; McMullin \& Raggo, 2020) within the grantor-grantee relationship affect the grantee's organizational capacity, that is, the "capabilities of an organization to improve its effectiveness and sustainability" (Cornforth \& Mordaunt, 2011, p. 431). The results of our multivariate analysis endorse the hypotheses that both operative support and goal congruence between grantor and grantee are positively correlated with the organizational capacity of the grantee. Our results likewise suggest that the benefits of increased oversight prevail over the drawbacks.

Our contribution to the literature is threefold. First, we add to the research on comprehensive philanthropy (Ma \& Konrath, 2018; Rogers, 2015). A growing literature on the nonprofit sector emphasizes the benefits of adopting a model of broadened participation (Clerkin \& Quinn, 2019) that goes beyond mere funding and enhances efficiency (Boesso \& Cerbioni, 2019; Coupet \& Berret, 2019), accountability (Brendan \& Quinn, 2019), social impact (Maya-Jariego et al., 2020), and legitimacy (Leardini et al., 2019). We contribute by rigorously studying the grantor-grantee relation, specifically the roles that operative support, goal alignment, and oversight can play in improving organizational capacity, as measured by the grantee's resources and management capacity and program development capacity. 
Second, we speak to the literature that emphasizes the importance of empathy, goal alignment, and trust in the third sector (Vangen \& Huxham, 2003). We do so by showing that goal alignment not only correlates positively and significantly with the capacity development of the grantee but also mutes the significance of oversight. In the perspective of practitioners, an unpleasant relation rich in oversight and control may lead to very different long-term outcomes compared to a fruitful, dialoguebased relation, even if the short-term achievement is the same. In spite of the specificities of the nonprofit sector, collecting data directly from grantees may also prove useful in other settings where the grantor-grantee scheme is relevant and the grantee's effectiveness is key (Maier et al., 2016).

Third, we enrich the literature on the managerialization of the nonprofit sector (Anheier, 2005; Hume \& Leonard, 2014; Laurett \& Ferreira, 2018). Since FOB boards consider themselves relatively familiar with the managerial dimension (Boesso et al., 2017), our quantitative results are useful to grantors to analyze the costs and benefits of enhancing their relation with grantees.

This paper is structured as follows: Sect. 2 reviews the literature, Sect. 3 posits the testable hypotheses, Sect. 4 describes the research method and data, Sect. 5 illustrates the empirical results, and Sect. 6 concludes.

\section{Literature review: the relationship between grantors and grantees}

Sustainability seems to be a first-order concern, with recent data from the National Center on Charitable Statistics suggesting that around $30 \%$ of nonprofits fail after 10 years (Ebarb, 2019). Just a few years ago, Forbes (Alman, 2016) projected that half of nonprofits would be at risk of failing due to the lack of adequate leadership, strategic plans, and accountability standards. In the academic literature, Despard (2017) identified the lack of non-financial support as one of the most critical barriers to the development of social innovation. More recently, Qu and Daniel (2020) and Peng et al. (2019) tackled how grantees can optimize their fundraising by focusing on financial efficiency, media visibility, and accreditation status and explained how closer relationships with donors improve these three skills.

Accordingly, third sector actors are increasingly being pushed to adopt managerial approaches that can guide their social mission toward more effective fulfillment (Maier et al., 2016; Minà et al., 2020; Rey-García et al., 2019; Suykens et al., 2020). In the Italian context, FOB boards seem to be skilled enough to provide their grantees with support that goes beyond money (Boesso et al., 2017). In principle, foundations can help their grantees address the most pressing social needs in a sustainable way (Leardini et al., 2017) by activating fruitful synergies among grantees and signaling other public or private funders (including market exchanges, sponsorships, donations, and grants) as well as advancing the state of knowledge and practice to improve grantees' performance (Porter \& Kramer, 1999). Foundations may provide several forms of support, ranging from legal and administrative to operational, in multiple areas, including goal assessment, network creation, SWOT analysis, and impact evaluation (Cornforth \& Mordaunt, 2011). Importantly, foundations may share their best practices in terms of processes and performance measurement 
(McMullin \& Raggo, 2020). Nonprofit literature has largely emphasized the need for a complex grantor-grantee relation that goes beyond the mere funding dimension (CEP, 2017) and how such interactions may benefit the social impact of beneficiaries in both intended and unintended ways (Benjamin, 2020). Dhanani and Connolly (2015) showed that non-governmental organizations (NGOs) are more accountable and achieve higher goals whenever they are more involved with their donors. Sen (2013) added that a larger influence of donors on beneficiaries can shift the focus toward long-term sustainable change.

Foundations have discretion as to the type of relation they create with their grantees, whether one-shot or enduring. The natural question is whether the latter can lay the grounds for knowledge transfer from foundations to grantees. Partnering has already proven successful as a way to transfer knowledge in a different yet still informative setting, namely, private equity and venture capitalism (Porter \& Kramer, 1999). Typically, private equity funds develop target firms by analyzing their business plans, monitoring results, strengthening managerial skills, and facilitating cooperation with other stakeholders (De Clercq \& Sapienza, 2006). Several studies have explored the possibility of extending managerial approaches to the nonprofit sector (Alexius \& Grossi, 2018; Bish \& Becker, 2015). Letts et al. (1997) first suggested that foundations should adopt a venture capitalist approach to support the capacity development of the nonprofit organizations they fund. In their view, this goal can be achieved through (i) closer relationships between foundations and grantees, (ii) higher grant amounts over sustained periods, (iii) performance measurement, and (iv) the adoption of exit strategies. This approach opens the way to concepts like "strategic philanthropy" (Porter \& Kramer, 1999), "venture philanthropy" (Moody, 2008), and "high-engagement philanthropy" (Herrold, 2006).

\section{Hypotheses}

\subsection{Grant-making foundations and grantees: room for skill transferring?}

Whether the model of knowledge transfer actually works (CEP, 2008, 2017) in the world of philanthropy is ultimately an empirical question. On the one hand, the idea of close cooperation is indeed well rooted in the world of philanthropy, where "partnering brings significant impact on the effectiveness of funders and on the strengthened capacity of grantees by creating a mutual culture of trust" (Ricciuti \& Swierczynska, 2018, p. 11). In this regard, Cornforth and Mordaunt (2011, p. 433) pointed out how a nonprofit organization could improve its "organizational capacity building" by effectively exploiting training, consultancy, financial support, and other forms of external support. The authors suggested that grantors should activate empowerment processes among their grantees.

A close grantor-grantee relation that goes beyond mere financing may be beneficial to the grantees even when managerial skills have been acquired. For instance, nonprofit organizations with a strong managerial orientation may struggle to gain donors' confidence when hiring a highly paid executive is perceived as a deviation from the organization's mission rather than an investment in its effectiveness. 
De Azevedo and de Aguiar (2020, p. 9) showed experimentally that "the negative effects of paying higher executive compensation levels only occur in the absence of information about a third-party endorsement but not in its presence." In addition, they raised a fascinating empirical question-beyond the scope of our paper-of whether the quality (intensity) of such an endorsement also matters.

On the other hand, grantees may refuse foundation support because of lack of trust (Vangen \& Huxham, 2003), perceived misalignment in the degree of specialization and goals, or internal consolidated and hard-to-change policies and practices. While these mechanisms may well be at work, and with goal alignment as the object of the next hypothesis, we expect foundation support to be on average well received, given the salience of the financial and future funding dimensions for the survival of nonprofit organizations.

The lack of managerial and financial skills among third sector organizations and the suggestive analogy between partnering in private equity and non-money support in the third sector converge in the following hypothesis.

Hypothesis 1 The grantor's non-financial support is positively associated with the grantee's organizational capacity development.

\subsection{Role of goal alignment between grantor and grantees}

Building organizational capacity in nonprofit organizations requires managers who possess (1) "big picture" skills, (2) the ability to address agency issues, and (3) coaching aptitudes (Austin et al., 2011). In particular, the ability to establish relationships with grantors and recognize their role and responsibilities as grantees is pivotal in solving external agency issues and, consequently, teaching to mitigate internal conflicts.

The difference in managerial and financial skills between foundations and grantees may be the basis of a misalignment in their objective functions, specifically in the weight attributed to sustainability and efficiency. Goal conflict is an essential component of agency theory and is shaped around the delegation problem typical of the owner-manager relationship in the for-profit sector (Haugen \& Senbet, 1981). Delegation is also at the heart of both agency theory and the foundation-grantee relationship. As chair of the Edna McConnell Clark Foundation, Bailin (2003, p. 636) emphasized that "foundations succeed when their grantees grow stronger, achieve more, and gain stature for leadership." Caers et al. (2006) discussed to what extent nonprofit organizations can tap into agency theory and the principal-agent model - notwithstanding the conceptual difficulty of clearly identifying principals and agents in this case-as well as take a stand on the utility function of each stakeholder.

For the nonprofit sector, Van Puyvelde et al. (2012) suggested that the principal-agent model should be enriched with elements from stewardship theory, which implies - at least according to one of its two branches-that "even when the interests of the agent and the principal are not aligned, the agent can attain a higher utility level by acting in the principal's interest because doing so might lead to 
opportunities for desired personal outcomes such as achievement, affiliation, and self-actualization" (p. 435). Along these lines, Maier et al. (2016) showed that third sector players perceive their funders more as stewards than as principals.

We can therefore think of the grantee's objective function as a combination of its own goals and the foundation's goals, where the foundation attaches relatively more importance to the managerial and financial dimensions because of its stronger managerial background. How do we expect the weight attached to the foundation's priorities to vary across matches of foundations and grantees? We conjecture that this weight will increase along with the grantee's perceived goal alignment with the foundation. In other words, we expect that a grantee whose mission is relatively more aligned with that of its funder's is more prone to invest in the relationship and exploit it so as to benefit from the personal outcomes underlying stewardship theory and, consequently, better outcomes overall (Chapman \& Varda, 2017). Accordingly, we posit our second hypothesis:

Hypothesis 2 Goal alignment between grantor and grantee is positively associated with the grantee's organizational capacity development.

\subsection{Effect of oversight mechanisms}

Since the success of foundations closely depends on the outcomes of their grantees' projects (Bailin, 2003), foundations are likely to be at least as concerned about delegating as owners are in the for-profit sector and therefore incentivized to oversee their grantee's actions.

Oversight is a potentially broader concept than support, as it implies that foundations do not just offer advice but rather directly enter the grantee's decision-making. Inter-organizational control literature suggests that the primary purpose of control exercised through oversight lies in creating the conditions that motivate organizations to achieve desirable or predetermined outcomes (Fisher, 1995). However, oversight can be a complex concept that involves multiple mechanisms, both formal (i.e., outcome and behavior control) and informal (i.e., social control; see Dekker, 2004), which do not necessarily have same-sign consequences on the relation among the organizations involved. Dekker (2004) explained how, for instance, formal control mechanisms (e.g., goal setting, planning, programs, rules, reporting, cost and quality control, performance and behavior monitoring and rewarding), although helpful in reducing performance ambiguity and inducing desirable behavior, may harm trust, which is usually at the heart of social control. "Extensive use of formal control suggests a lack of belief in one's goodwill or competence and therefore results in a damaging effect on relational trust (...)," but at the same time, "the use of formal control mechanisms may actually enhance a trusting relationship, by narrowing the domain and severity of risk (...) and by their objectivity and provision of a track record about the other's performance, behaviours and skills" (Dekker, 2004, p. 34). While Dekker (2004) referred to the moderating role of trust in control mechanisms (both formal and informal) that consider peer-to-peer relationships, such as strategic alliances, a similar reasoning could apply to hierarchical relationships, such as 
the grantor-grantees one. In fact, the pressure induced by the oversight could likely affect the grantee's (perceived) improvement brought about by the foundation. Thus, similarly, there may be opposing forces in the relation between foundation oversight and grantees' capacity development. On the one hand, oversight may simply benefit the grantees, as support does, while eliminating the inefficiencies of learning (time, initial mistakes, and misunderstandings). On the other hand, top-down oversight may distort the perception of NGO priorities and the effectiveness of aid (Agyemang et al., 2017) as well as the notions of accountability and development (Awio et al., 2011). According to this view, oversight "invites an opposing ideology and set of practices that threaten the nonprofit sector's ability to remain distinct from other sectors and uniquely address social problems" (Sanders \& McClellan, 2014, p. 64).

Therefore, the sign of the relation between foundation oversight and grantees' reliance on the foundation is in principle ambiguous.

Hypothesis 3 Grant oversight mechanisms are associated with the grantee's organizational capacity development.

Figure 1 presents the conceptual model tested in this research, along with the three hypotheses defined.

\section{Research method}

\subsection{Institutional setting}

In Italy, FOBs play a major role as grantors in helping grantees (e.g., associations, cooperatives, and operating foundations) achieve their strategic goals. As of 2017, FOBs were managing financial portfolios worth $€ 39.6$ billion and recording social expenditures of more than $€ 1$ billion (ACRI, 2018) to assist underprivileged people, education, volunteer organizations, healthcare and scientific research, and arts and culture (Hinna \& Monteduro, 2017). Italian FOBs constitute a fairly homogeneous

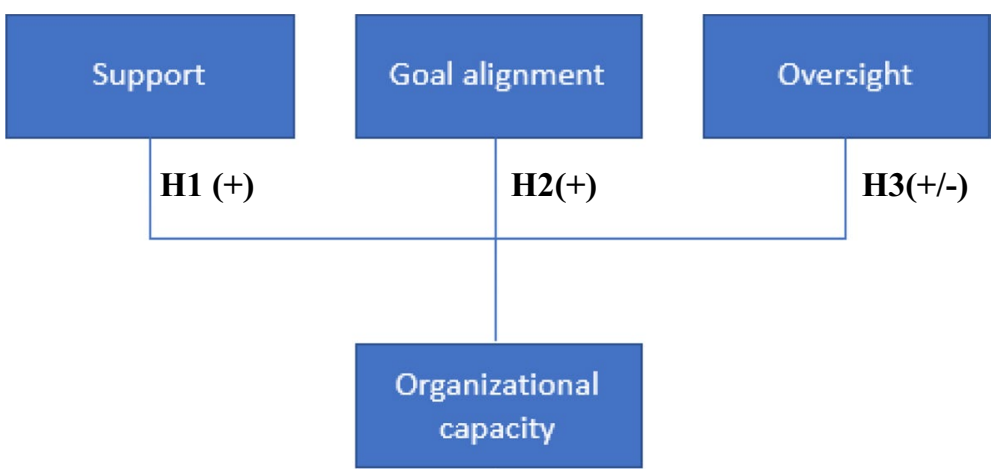

Fig. 1 Tested model 
industry within a single country, boasting the fifth largest amount of foundational assets worldwide (87 billion according to GPR, 2018), below only the US (890), the Netherlands (108), Germany (93), and Switzerland (88) but above the UK (84), France (30), and Spain (29). Italian FOBs have also been able to respond to economically and socially disadvantaged circumstances by adopting formalized strategies and more transparent governance mechanisms (Boesso et al., 2017).

In 2015, the FOBs and the Italian Ministry of Economy and Finance (the oversight authority) signed a memorandum of understanding in which FOBs committed to better perform their governance, transparency, and investment diversification. After signing the memorandum of understanding, all the foundations amended their bylaws by the 2017 deadline, redefining their governance, mechanisms for election of board members, rules for accountability, and other aspects of their activities. More specifically, they committed to a risk-adverse investment policy, zero indebtedness, a maximum 4-year term for trustees, gender balance, reasonable compensation for trustees, independence and professional status of trustees, and formalized strategic plans and grant-giving procedures, among various other elements, to provide greater transparency and better civil service. Next, in late 2017, the government introduced a more widespread reform for the whole Italian third sector (including all grantees), emphasizing the role of nonprofit institutions in the delivery of private welfare services and calling for higher professionalism.

In sum, the 2015 memorandum of understanding qualified FOBs as pivotal players for the transparent financial support of social projects carried out by other nonprofit organizations, and the 2017 reform of the Italian third sector emphasized the growing role of nonprofit organizations in modern societies and the need for a stable financial and managerial structure. Accordingly, grantors and grantees are expected to increase their relationships for supporting and complementing the national budget allocated to welfare services. In this context, our research is timely as we put a dimension of utmost importance, namely, the capacity development of grantees, at the center of our investigation.

\subsection{Data and sample}

The data were collected in 2018 through a questionnaire submitted to a sample of grantees financed by Italian FOBs. We started by collecting the list of grantees' names and related information from the 2016 annual reports of Italian FOBs. From this list, we identified those receiving grants of $€ 2000$ or more as potential respondents to minimize the risk of observing relations with no-more-than-minimal interactions. We then administered the questionnaire to each of our 1211 potential respondents, whether nonprofit associations, operating foundations, or social cooperatives. A preliminary version of the questionnaire was presented to the national professional association, and its validity was tested with a focus group of four foundations.

The questionnaire was sent to the respondents in October 2018. It remained available online for a month, and four email reminders were sent. We received 242 complete questionnaires from nonprofit organizations associated with 26 Italian FOBs (30\% of the FOB population), yielding a response rate of $20 \%$. Therefore, the 
final sample included 242 organizations, 154 of which are nonprofit associations, 45 are social cooperatives, and 43 are operating foundations. The organizations in our sample operate primarily in the fields of arts and culture $(38 \%)$, education (15\%), health (19\%), and volunteering (12\%). In terms of size, 32\% declare revenues below $€ 50.000,14 \%$ between $€ 50.001$ and $€ 100.000,26 \%$ between $€ 100.001$ and $€ 500.000$, and $27 \%$ above $€ 500.001$. A total $69 \%$ employ fewer than 10 workers. Forty percent of the questionnaires were filled in by people who hold the position of chair or deputy chair, $18 \%$ are general directors, while the rest serve in other roles, including project manager. Among the 26 FOBs represented in our sample, 8 are classified as large foundations, 6 as medium-large, 3 as medium, 7 as medium-small, and 2 as small.

\subsection{Measures}

The dependent variable was based on the scale developed by Despard (2017) to measure the organizational capacity of nonprofits. Respondents rated a series of items describing to what extent the organizational capacity of their organizations developed through the help of the granting foundation. The items were rated on a seven-point Likert scale, from 1 ("not at all") to 7 ("extremely"). The survey questions used in the empirical analysis are provided in Appendix 1.

Confirmatory factor analysis with VARIMAX rotation was undertaken to identify the dimensions of organizational capacity that capture most of the variation, with a loading of 0.60 as the cutoff point for the factors. The analyses retained two factors with eigenvalues greater than 1 , Resources and management capacity and Program development, accounting for $62 \%$ of the variance (Table 1). Retaining these two factors is consistent with the theoretical constructs described in Despard (2017).

Cronbach's alpha coefficients were calculated to assess the internal consistency of items. For Resources and management capacity and Program development, the Cronbach's alphas were 0.90 and 0.84 , respectively, indicating satisfactory internal consistency.

These two constructs provided the two measures of organizational capacity that were used as dependent variables in the regression analyses. The items that loaded for Resources and management capacity are related with the increased ability of the organization to manage its resources. Among these items, the ones with the highest average scores were the development of capacities to use a budgeting process, the use of financial management systems, and the provision of professional development to staff. Meanwhile, the items that loaded on Program development were related to increases in the services offered and the number of beneficiaries served.

To help explain how the foundation's assistance is deployed and test the first hypothesis, respondents were asked to evaluate on a seven-point scale the extent to which the foundation provided them with various types of support. We proposed the same forms of assistance that the CEP (2008) proposes as frequently provided to grantees.

To test our second hypothesis, we used the scale developed by De Clercq and Sapienza (2006), which measures goal congruence in the relational capital between 
Table 1 Factor analysis (dependent variables)

\begin{tabular}{|c|c|c|c|}
\hline Variable & Mean & Factor 1 & Factor 2 \\
\hline \multicolumn{4}{|c|}{ Resources and management capacity (alpha 0.90) } \\
\hline New sources non-government funding & 3.07 & 0.77 & \\
\hline New sources government funding & 2.95 & 0.75 & \\
\hline Client data system & 2.82 & 0.72 & \\
\hline Financial management system & 3.18 & 0.71 & \\
\hline Fundraising plan & 3.05 & 0.65 & \\
\hline Staff professional development & 3.14 & 0.64 & \\
\hline Staff leadership development & 2.48 & 0.62 & \\
\hline Volunteer management & 3.08 & 0.61 & \\
\hline Budgeting process & 3.76 & 0.61 & \\
\hline \multicolumn{4}{|l|}{ Program development capacity (alpha 0.84 ) } \\
\hline Increase scope of services & 3.65 & & 0.85 \\
\hline Services new clients or communities & 4.01 & & 0.81 \\
\hline Increase number of clients & 4.02 & & 0.80 \\
\hline
\end{tabular}

This table reports latent factors and loading items used as dependent variables. Values less than 0.300 are not specified. A factor loading of 0.600 is used as cutoff point for the factors

venture capital (VC) and VC-backed companies. In this case, respondents used a seven-point Likert scale to rate the commonalities between their vision, objectives, and attitude and those of the foundation.

To test the third hypothesis, we used the framework developed by Delfin and Tang (2008), which assesses the oversight mechanisms that foundations activate to supervise their grantees. Respondents were asked to use a seven-point Likert scale to rate the frequency with which the foundation adopted particular oversight mechanisms to monitor the grants offered.

The results of the factor analysis on explanatory variables are reported in Table 2 and confirm that three factors account for $55 \%$ of the variance. Six items load on the first factor, Support, with the highest average scores obtained by the items "assistance in the development of performance measures" and "assistance in strategic and financial planning." Three items, all with high average scores, load on the second factor, Goal alignment, and five items load on the third factor, Oversight. Among the items that load on Oversight, the highest average score is reported by the item "expost evaluation of the results." Cronbach's alpha coefficients were also calculated to assess the internal consistency of the items. The Cronbach's alphas for Support, Goal alignment, and Oversight were $0.86,0.87$, and 0.78, respectively, indicating satisfactory internal consistency.

Finally, several control variables taken from the literature were added to account for grant characteristics and recipient organization profiles (Delfin \& Tang, 2008). Specifically, we controlled for the size of the grant calculated as the natural logarithm of the grant amount (Grant amount); the length of the project financed using an indicator variable that is equal to 1 if the length of the financed project is more than 1 year, and 0 otherwise (Multi-year project); and the type of selection process, 
Table 2 Factor analysis (research variables)

\begin{tabular}{|c|c|c|c|c|}
\hline Variable & Mean & Factor 1 & Factor 2 & Factor 3 \\
\hline \multicolumn{5}{|l|}{ Support (alpha 0.86) } \\
\hline Insights and advice on the field & 2.70 & 0.83 & & \\
\hline Strategic and financial planning advice & 2.80 & 0.78 & & \\
\hline Development of performance measures & 2.84 & 0.76 & & \\
\hline Introduction to leaders in the field & 2.15 & 0.74 & & \\
\hline Communication/marketing assistance & 2.73 & 0.71 & & \\
\hline Fundraising assistance & 1.86 & 0.66 & & \\
\hline \multicolumn{5}{|l|}{ Goal alignment (alpha 0.86 ) } \\
\hline Congruence of objectives & 5.15 & & 0.92 & \\
\hline Enthusiasm in pursuing the same objectives & 4.93 & & 0.85 & \\
\hline Alignment of vision on the issues to tackle & 5.20 & & 0.83 & \\
\hline \multicolumn{5}{|l|}{ Oversight (alpha 0.78) } \\
\hline Emphasizing results and ideas for public dissemination & 3.26 & & & 0.78 \\
\hline Identification of issues to tackle & 3.22 & & & 0.77 \\
\hline Specification of activities to undertake & 3.39 & & & 0.76 \\
\hline Identification of organizations to work with & 1.89 & & & 0.64 \\
\hline Ex-post evaluation of results & 4.04 & & & 0.63 \\
\hline
\end{tabular}

This table reports latent factors and loading items used as research variables. Values less than 0.300 are not specified. A factor loading of 0.600 is used as cutoff point for the factors

that is, whether competitive or not, using an indicator variable equal to 1 if the selection occurred through a competitive bid, and 0 otherwise (Competitive selection). We also controlled for the type of grantee organization by using two indicator variables (Association and Social cooperative) and the stage of maturity of the organization (i.e., whether established for more than 10 years). Finally, we controlled for the size of the organization (i.e., using the amount of revenues realized), which is an intrinsic determinant of organizational capacity.

All the scores were normalized between 0 and 1 . The full list of variables is presented in Appendix 2. All the regression models included "area of intervention" fixed-effects to control for systematic differences across sector types. To this end, we categorized eight operational areas/sectors: arts and culture, education, local development, environmental protection, health, volunteering, research and development, and others.

\section{Results}

Table 3 reports descriptive statistics of the variables included in the model. The mean of Resources and management capacity $(0.36 ; \mathrm{SD}=0.21)$ is lower than that of Program development $(0.51 ; \mathrm{SD}=0.27)$. Among the other research variables, the mean of Support is $0.25(\mathrm{SD}=0.21)$, way below the mean of Goal alignment at 0.68 $(\mathrm{SD}=0.25)$ and lower than the mean of Oversight at $0.37(\mathrm{SD}=0.26)$. The means of 
Table 3 Descriptive statistics

\begin{tabular}{llllllr}
\hline Variable & N & Mean & SD & P.25 & Median & P.75 \\
\hline Resources and management capacity & 242 & 0.36 & 0.21 & 0.17 & 0.37 & 0.50 \\
Program development capacity & 242 & 0.51 & 0.27 & 0.33 & 0.50 & 0.67 \\
Support & 242 & 0.25 & 0.21 & 0.08 & 0.21 & 0.39 \\
Goal alignment & 242 & 0.68 & 0.25 & 0.56 & 0.70 & 0.83 \\
Oversight & 242 & 0.37 & 0.26 & 0.17 & 0.30 & 0.57 \\
Competitive selection & 242 & 0.72 & 0.45 & 0.00 & 1.00 & 1.00 \\
Multi-year projects & 242 & 0.78 & 0.42 & 1.00 & 1.00 & 1.00 \\
Grant amount (log) & 242 & 9.78 & 1.37 & 8.70 & 9.78 & 10.58 \\
Association & 242 & 0.64 & 0.48 & 0.00 & 1.00 & 1.00 \\
Social cooperative & 242 & 0.19 & 0.39 & 0.00 & 0.00 & 0.00 \\
Mature organization & 242 & 0.74 & 0.44 & 0.00 & 1.00 & 1.00 \\
Size & 242 & 1.48 & 1.20 & 0.00 & 2.00 & 3.00 \\
\hline
\end{tabular}

This table reports the descriptive statistics of all variables used in the analysis. All variables are defined in Appendices 1 and 2

Competitive selection and Multi-year projects are 0.72 and 0.78 , respectively, meaning that a competitive selection occurred in $72 \%$ of the cases, and $78 \%$ of the grants financed multi-year projects. The mean of Grant amount is $9.78(\mathrm{SD}=1.37)$ while the means of Association and Social cooperatives are 0.64 and 0.19 , respectively. Thus, $64 \%$ of the organizations in the sample are associations and $19 \%$ are social cooperatives. Finally, the mean of Size is $1.48(\mathrm{SD}=1.20)$.

Table 4 reports correlations among the variables included in the model. As expected, Support and Goal alignment are positively and significantly correlated with Resources and management capacity and Program development. In addition, Oversight attracts a positive and precise coefficient, suggesting that its benefits prevail over the drawbacks. Competitive selection, Multi-year projects, and Grant amount also have positive and significant correlations with the dependent variables. Other relevant and significant correlations emerge between Social cooperative, Program development, and Support.

To test our three hypotheses, we first examined the effect of Support, Goal alignment, and Oversight on Resources and management capacity. Our hypotheses predict that the coefficients on Support (Hypothesis 1) and Goal alignment (Hypothesis 2) are positive while we are agnostic regarding the sign of the coefficient attracted by Oversight (Hypothesis 3).

We find that (i) conditional on the size of the financial support, the amount of non-financial support provided by the foundation is positively correlated with the organizational capacity of the grantee; (ii) a higher perception of goal congruence between grantor and grantee is positively associated with the organizational capacity development of the grantee; and (iii) stronger grant oversight mechanisms are positively associated with the organizational capacity development of the grantee.

When considered one by one, all the coefficients of the three main variables are positive and significant at the $1 \%$ level (Table 5). When the three variables are 


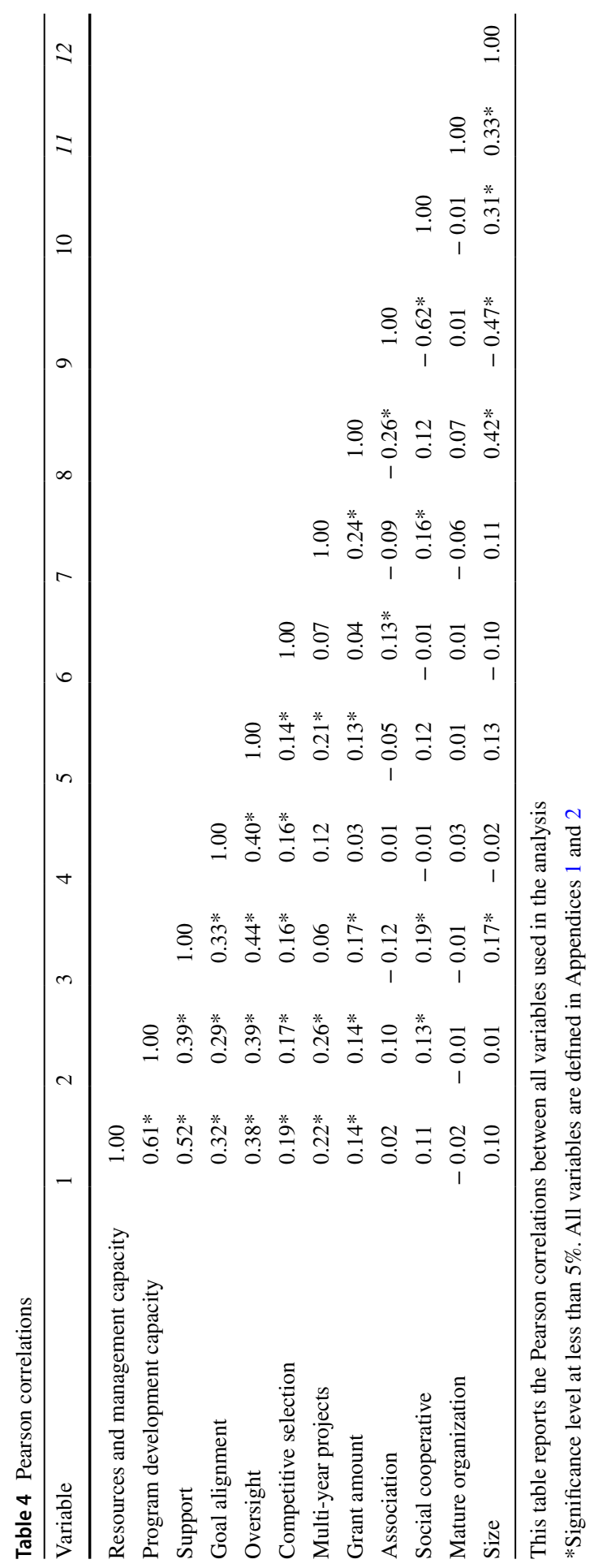


Table 5 OLS regression (resources and management capacity)

\begin{tabular}{|c|c|c|c|c|c|c|c|c|}
\hline & \multicolumn{8}{|c|}{ Dependent variable: resources and management capacity } \\
\hline & \multicolumn{2}{|l|}{$\mathrm{H} 1$} & \multicolumn{2}{|l|}{$\mathrm{H} 2$} & \multicolumn{2}{|l|}{$\mathrm{H} 3$} & \multicolumn{2}{|c|}{ Augmented model } \\
\hline & Coeff. & t-stat & Coeff. & t-stat & Coeff. & t-stat & Coeff. & t-stat \\
\hline Support & 0.493 & $8.058 * * *$ & & & & & 0.415 & $6.040 * * *$ \\
\hline Goal alignment & & & 0.247 & $4.773 * * *$ & & & 0.107 & $1.975 * *$ \\
\hline Oversight & & & & & 0.237 & $4.589 * * *$ & 0.072 & 1.303 \\
\hline $\begin{array}{l}\text { Competitive selec- } \\
\text { tion }\end{array}$ & 0.029 & 1.030 & 0.056 & $1.903 *$ & 0.053 & $1.816^{*}$ & 0.021 & 0.789 \\
\hline Multi-year projects & 0.087 & $2.839 * * *$ & 0.060 & $1.705 *$ & 0.058 & 1.633 & 0.071 & $2.276^{* * *}$ \\
\hline Grant amount & -0.000 & -0.027 & 0.008 & 0.741 & 0.007 & 0.625 & 0.000 & 0.034 \\
\hline Association & 0.067 & $1.910 *$ & 0.091 & $2.410 * *$ & 0.078 & $2.049 * *$ & 0.066 & $1.839 *$ \\
\hline Social cooperative & 0.024 & 0.621 & 0.080 & $2.074 * *$ & 0.060 & 1.468 & 0.028 & 0.749 \\
\hline $\begin{array}{l}\text { Mature organiza- } \\
\text { tion }\end{array}$ & -0.013 & -0.467 & -0.033 & -1.113 & -0.024 & -0.834 & -0.016 & -0.599 \\
\hline Size & 0.011 & 0.778 & 0.026 & $1.830 *$ & 0.018 & 1.238 & 0.013 & 0.915 \\
\hline Constant & 0.110 & 0.991 & -0.058 & -0.481 & 0.064 & 0.553 & 0.043 & 0.382 \\
\hline$p$ & 0.000 & & 0.000 & & 0.000 & & 0.000 & \\
\hline$R^{2}$ & 0.339 & & 0.209 & & 0.207 & & 0.363 & \\
\hline Observations & 242 & & 242 & & 242 & & 242 & \\
\hline
\end{tabular}

This table reports the main results of OLS regressions to test $\mathrm{H} 1, \mathrm{H} 2$, and $\mathrm{H} 3$

$* * *, * *$, and * indicate significance at the $1 \%, 5 \%$, and $10 \%$ levels, respectively, using a two-tailed test. Please see Appendix 2 for variable definitions

considered together (Table 5), Support is still positive and significant at the $1 \%$ level, Goal alignment is positive and significant at the 5\% level, and the significance of Oversight fades. Multi-year project is positive and significant at the 5\% level, so the length of the financed project is, as expected, associated with the development of the grantee's resources and management capacity. Grant amount, Social cooperative, Competitive selection, and Mature Organization are not significant while Association is positive and significant at the $10 \%$ level.

The same regression analyses are replicated using Program development as the dependent variable. As expected, the coefficients of Support (Hypothesis 1) and Goal alignment (Hypothesis 2) are all positive and significant at the $1 \%$ level (Table 6). Likewise, Oversight (Hypothesis 3) attracts a precise coefficient, and the positive sign supports the contention that the benefits of oversight prevail over the drawbacks. In the augmented model, the three variables remain significant at the $1 \%, 10 \%$, and 5\% levels, respectively. Multi-year project continues to be positively and significantly associated to Program development while Grant amount, Competitive selection, and Mature Organization are not significant. Association and Social cooperative are positive and significant at the $1 \%$ and 5\% levels, respectively.

Overall, the results support our hypotheses that the amount of operative support provided by the foundation (Hypothesis 1) and a higher perception of goal congruence between grantor and grantees (Hypothesis 2) are positively correlated with both 
Table 6 OLS regression (program development)

\begin{tabular}{|c|c|c|c|c|c|c|c|c|}
\hline & \multicolumn{8}{|c|}{ Dependent variable: program development capacity } \\
\hline & \multicolumn{2}{|l|}{$\mathrm{H} 1$} & \multicolumn{2}{|l|}{$\mathrm{H} 2$} & \multicolumn{2}{|l|}{$\mathrm{H} 3$} & \multicolumn{2}{|c|}{ Augmented model } \\
\hline & Coeff. & t-stat & Coeff. & t-stat & Coeff. & t-stat & Coeff. & t-stat \\
\hline Support & 0.453 & $5.926 * * *$ & & & & & 0.323 & $3.459 * * *$ \\
\hline Goal alignment & & & 0.282 & $4.020 * * *$ & & & 0.132 & $1.752 *$ \\
\hline Oversight & & & & & 0.307 & $5.200 * * *$ & 0.161 & $2.245^{* *}$ \\
\hline $\begin{array}{l}\text { Competitive selec- } \\
\text { tion }\end{array}$ & 0.028 & 0.754 & 0.049 & 1.280 & 0.042 & 1.098 & 0.015 & 0.423 \\
\hline Multi-year projects & 0.129 & $3.208 * * *$ & 0.100 & $2.375 * *$ & 0.094 & $2.240 * *$ & 0.103 & $2.577 * *$ \\
\hline Grant amount & 0.015 & 1.150 & 0.023 & $1.705^{*}$ & 0.020 & 1.532 & 0.016 & 1.229 \\
\hline Association & 0.152 & $3.557 * * *$ & 0.173 & $3.924 * * *$ & 0.156 & $3.559 * * *$ & 0.148 & $3.453^{* * *}$ \\
\hline Social cooperative & 0.125 & $2.536^{* *} *$ & 0.177 & $3.384 * * *$ & 0.153 & $2.870 * * *$ & 0.130 & $2.583 * *$ \\
\hline $\begin{array}{l}\text { Mature organiza- } \\
\text { tion }\end{array}$ & -0.001 & -0.014 & -0.020 & -0.503 & -0.010 & -0.251 & -0.005 & -0.123 \\
\hline Size & -0.006 & -0.319 & 0.009 & 0.538 & -0.001 & -0.070 & -0.004 & -0.211 \\
\hline Constant & 0.007 & 0.053 & -0.178 & -1.230 & -0.039 & -0.282 & -0.081 & -0.580 \\
\hline$p$ & 0.000 & & 0.000 & & 0.000 & & 0.000 & \\
\hline$R^{2}$ & 0.284 & & 0.239 & & 0.255 & & 0.325 & \\
\hline Observations & 242 & & 242 & & 242 & & 242 & \\
\hline
\end{tabular}

This table reports the main results of OLS regressions to test $\mathrm{H} 1, \mathrm{H} 2$, and $\mathrm{H} 3$

$* * *, * *$, and $*$ indicate significance at the $1 \%, 5 \%$, and $10 \%$ levels, respectively, using a two-tailed test. Please see Appendix 2 for variable definitions

the resources and management capacity and program development of the grantee. Our results likewise suggest that the benefits of increased oversight prevail over the drawbacks (Hypothesis 3).

\subsection{Additional analyses and robustness checks}

To address the potential bias toward positive feedback in surveys, the questionnaire also asked about the difficulties experienced by the surveyed organizations. Specifically, respondents used a seven-point scale to rate the extent to which they faced various types of difficulties over the duration of the grant. Table 7 shows the mean scores of the difficulties reported depending on the type of organization represented (association, social cooperative, and operating foundation).

The data show that associations report the highest difficulties with operating activities, such as attracting new human resources, managing volunteers, and finding new funders. Together with our prior findings, this result can be interpreted as organizations benefitting the most from capacity-building processes. Social cooperatives report they struggle to evaluate their own performance. Identifying funders turns out to be the most challenging task for all organizations, thus confirming the substantial lack of financial management skills in the third sector. 
Table 7 ANOVA difficulties

\begin{tabular}{lllll}
\hline Variable & $\begin{array}{l}\text { Associations } \\
(\mathrm{N}=155)\end{array}$ & $\begin{array}{l}\text { Social coopera- } \\
\text { tives }(\mathrm{N}=45)\end{array}$ & $\begin{array}{l}\text { Operating founda- } \\
\text { tions (N=45) }\end{array}$ & $\mathrm{F}$ \\
\hline Attract new human resources & 0.58 & 0.46 & 0.44 & $4.78^{* * *}$ \\
Retain employees & 0.25 & 0.21 & 0.21 & 0.50 \\
Manage volunteers' work & 0.38 & 0.26 & 0.23 & $6.97 * * *$ \\
Identifying funders & 0.76 & 0.69 & 0.65 & $3.90^{* * *}$ \\
Operation planning & 0.36 & 0.41 & 0.31 & 1.25 \\
Financial planning & 0.48 & 0.49 & 0.41 & 1.37 \\
Performance evaluation & 0.39 & 0.54 & 0.44 & $4.85^{* * *}$ \\
\hline
\end{tabular}

This table reports the results of ANOVA tests for the difficulties reported by the surveyed organizations $* * *, * *$, and * indicate significance at the $1 \%, 5 \%$, and $10 \%$ levels, respectively

Additionally, the questionnaire investigates the use of support tools in the assessment of social impact, as suggested by Despard (2017). Respondents used a sevenpoint scale to evaluate the extent to which they increased the use of the proposed tools after the foundation's intervention. Table 8 reports the mean scores for the three types of organizations and shows a major increase for first-level qualitative analyses, such as interviews and focus groups with beneficiaries, cost-benefit analyses, and social value-added systems. Less evident is the effect on the use of more innovative instruments, such as social return on investment (SROI), randomized controlled trials, counterfactual analysis, and theory of change. The use of the proposed instruments, except for theory of change, is significantly higher in social cooperatives as this group is also the one that, probably because of its business-like nature and more deterministic approach, reports the greatest difficulty in evaluating its effectiveness.

Beyond the positive bias concern, we were worried about respondents in apical positions self-advertising and being overly optimistic in evaluating the relationship. Therefore, we conducted a sensitivity analysis, which dropped the responses

Table 8 ANOVA social impact measurement

\begin{tabular}{lllll}
\hline Variable & $\begin{array}{l}\text { Associations } \\
(\mathrm{N}=155)\end{array}$ & $\begin{array}{l}\text { Social coopera- } \\
\text { tives }(\mathrm{N}=45)\end{array}$ & $\begin{array}{l}\text { Operating founda- } \\
\text { tions (N=45) }\end{array}$ & $\mathrm{F}$ \\
\hline First-level qualitative analysis & 0.36 & 0.42 & 0.28 & $2.64 *$ \\
Costs-benefit analysis & 0.37 & 0.49 & 0.31 & $4.38^{* *}$ \\
Social value added & 0.20 & 0.36 & 0.11 & $9.83^{* * *}$ \\
Social return on investments & 0.12 & 0.26 & 0.09 & $7.83^{* * *}$ \\
Counterfactual analysis & 0.13 & 0.19 & 0.07 & $3.33^{* *}$ \\
Randomized controlled trials & 0.11 & 0.14 & 0.06 & $2.61^{*}$ \\
Theory of change & 0.17 & 0.22 & 0.11 & 2.10 \\
\hline
\end{tabular}

This table reports the results of ANOVA tests for social impact assessment tools $* * *, * *$, and $*$ indicate significance at the $1 \%, 5 \%$, and $10 \%$ levels, respectively 
of 97 chairs/deputy chairs from the sample. As an additional robustness check, we repeated the analyses using the number of employees working for the organization as a different proxy for size. The results obtained (untabulated for brevity and available upon request) from both analyses are qualitatively unaltered.

Moreover, we found no heterogeneity in the estimated relations across types of grantees: associations, social cooperatives and operating foundations. We repeated our main analysis by using two subsamples and adding interaction terms between type and research variables. First, we partitioned our sample in two: (a) 155 associations and (b) 45 social cooperatives and 45 operating foundations. (We merged social cooperatives and operating foundations as they are very similar in nature.) The results (untabulated for brevity) remain qualitatively similar across the two samples, with only the coefficient of Oversight turning out to be insignificant in subsample b. Second, we added the interactions between our main variables of interest (i.e., Support, Goal alignment, and Oversight) with Association. Once again, the results verify that our main effects are not subsumed to the nature of a specific grantee. Overall, we conclude that our main results are not driven by a particular form or type of grantee organization. This outcome is remarkable given the observed differences in perceived difficulties and managerial approach among types (Tables 7 and 8).

Finally, the fact that several of our variables display a positive correlation between each other (Table 4) does not imply low reliability of the items included in the questionnaire nor does it affect the goodness of our model estimates. Indeed, the scores were normalized so that they range between 0 and 1 . The Cronbach's alpha test performed on all our variables also indicates satisfactory internal consistency among questionnaire items. Lastly, to exclude any concerns about multicollinearity, we performed the variance inflation factor (VIF) diagnostic test on all regression coefficients. The mean VIF obtained was equal to 1.32, which is well below the recommended threshold of 10 (Hair et al., 1995), thus minimizing the risk of potential multicollinearity issues.

\section{Discussion and conclusions}

Considering the importance of the grantor-grantee relationship in the nonprofit sector (Benjamin, 2020), the literature underlines where collaboration can germinate and produce more effective philanthropy (Fairfield \& Wing, 2008). Therefore, the voice of grant recipients is crucial in determining whether and how the mechanisms proposed by the literature and practitioners to improve the strategic actions of foundations are perceived as useful and help the latter make good social use of their resources.

This research studies to what extent an "enriched" grantor-grantee relation (enriched beyond mere funding) contributes to the development of the grantee's organizational capacity according to the grantee's perception. Hypotheses on the role of non-financial support (Hypothesis 1), goal alignment (Hypothesis 2), and oversight (Hypothesis 3) are tested against a novel dataset obtained from a sample of grantees of Italian FOBs. The results of multivariate regression analyses show that, 
first, grantees who also receive non-financial support from their grantors see their organizational capacity improve. This development is not guaranteed a priori (Vangen \& Huxham, 2003); lack of trust, goal misalignment, and internal inertia may deter grantees from welcoming the advice and guidance of their grantors. Our result suggests that, at least in the Italian FOB context, these potential obstacles are-if anything - second order compared to the grantees' need to preserve their funding capacity and financial sustainability. Second, we confirm that goal alignment between the grantor and the grantee is beneficial for the grantee's growth (Chapman \& Varda, 2017) because the ability to establish relationships with grant-makers mitigates agency issues (Austin et al., 2011). Third, we find that, once controlled for non-financial support and goal alignment, increased oversight does (not) correlate significantly with the grantee's perceived program development capacity (resources and management capacity). This result is interesting as it reflects the tensions identified by the theory (Sanders \& McClellan, 2014); in particular, while increased oversight may reduce learning inefficiencies, a top-down approach may be detrimental in a nonprofit, trust-based context.

Our results speak directly to practitioners and policymakers working to improve the financial attractiveness and sustainability of nonprofit organizations worldwide. In the first place, a model of knowledge transfer between grantor and grantee may become a best practice to support the grantee's growth in an effective, cheap, and easy-to-accept way. Second, favoring grantor-grantee matches based on common goals and missions may be more efficient. Third, to a certain extent, increasing spending on oversight may be ineffective.

Our article puts forward a model of grantor-grantee relation enriched with nonfinancial support and built on goal alignment. The systematic creation of goalaligned matches would likely require policy interventions that discipline foundations' positioning in the market and grant application processes, the design of which is beyond the scope of our study. Among the approaches to capacity building identified in the literature (Cornforth \& Mordaunt, 2011), our framework is closest to the "engaged approach" adopted by the UK Charities Aid Foundation's (CAF) Grants Programme and based on direct and strong two-way relations between grant-makers, grantees, and consultants. Different from the "engaged approach" formulated by Cornforth and Mordaunt (2011), our framework hints at a prevalent role of grant-makers over consultants in advising and supporting grantees. Specifically, in our model, consultants would only fit as the result of a mutual acknowledgement between grantor and grantee that external skills are needed. Foundations themselves, when strong enough, are thought of as the main providers of financial and non-financial resources. If this profile potentially matches with a good fraction of Italian FOBs, then a cross-country evaluation of foundations' skill endowment will be a required step for future research to evaluate the generalizability of such a model. Modifying the "engaged approach" in a way that drastically reduces the role of external consultants clearly implies benefits and risks. On the plus side, replacing external consultants with grantors in the assessment of grantees' organizational needs is likely to keep grantees more committed and make them feel owners of any findings or recommendations (Cornforth \& Mordaunt, 2011). This result is to be expected especially within long-lasting grantor-grantee relations, where all the 
mutual knowledge accumulated in an informal and unstructured way will likely help grantors convey the reasons for organizational changes and grantees feel more in control of such changes. The main cost of this approach is that grantors may need to hire staff dedicated to the assessment process, especially because organizations' needs should be assessed systematically (Backer, 2000; Blumenthal, 2003), possibly once grantees are ready to welcome the outcome. According to Cornforth and Mordaunt (2011), foundations engaged in the capacity-building process likely need to reinforce their staff anyway. Enhancing grantors' role in providing non-financial support may be particularly beneficial to the aggregate human capital acquisition in the third sector, with potential positive externalities on other stages of the project implementation as well, such as the screening, selection, and evaluation of grant receivers. Importantly, increasing the human capital of foundations may be beneficial to timeliness, as long as grantors themselves are able to internally produce reports that can be directly shared with the grantees rather than passing from consultants onto grantors and eventually only grantees (Cornforth \& Mordaunt, 2011). According to Bateau et al. (2008), increasingly engaged foundations move toward giving fewer and larger grants. The consequences of such a trend in the Italian third sector should be carefully evaluated in future work.

We contribute to the academic literature in three ways. First, we add to the research on comprehensive philanthropy by shedding light on the anatomy of the grantor-grantee relation. Our findings align with the literature on the nonprofit sector that highlights the gains from adopting a model of broadened participation (Clerkin \& Quinn, 2019) that goes beyond mere funding and enhances efficiency (Boesso \& Cerbioni, 2019; Coupet \& Berrett, 2019), accountability (Brendan \& Quinn, 2019), social impact (Maya-Jariego et al., 2020), and legitimacy (Leardini et al., 2019). Second, we speak to the existing works that identify the role of empathy, goal alignment, and trust in the third sector (Vangen \& Huxham, 2003). In this respect, we show that goal alignment not only correlates positively and significantly with the capacity development of the grantee but also mutes the role of oversight. Third, we enrich the literature on the managerialization of the nonprofit sector (Anheier, 2005; Hume \& Leonard, 2014; Laurett \& Ferreira, 2018). For the Italian context, since FOB boards have a managerial heritage in terms of sharable skills (Boesso et al., 2017), our results are useful to grantors who hope to quantify costs and benefits from enhancing their relation with grantees. In an international perspective, our findings may be extended to grantors with a comparable internal organization.

This research has several limitations that call for discussion. First, we cannot compare perceptual measures of improvement with objective ones. Had we both, we could conduct a rigorous efficiency and effectiveness analysis, shedding light on whether perceptual data can enrich the evaluation of the long-term effects of the grantor-grantee relation beyond what short-term objective measures might report. In our analysis, perceptual data are of interest per se, and our methodological choice is motivated. Nonetheless, we acknowledge that there may be a discrepancy with objectively measured effectiveness. We tackle this possibility by gaining perspectives not solely from respondents covering an apical role but rather a set of different trustees. We also enrich our empirical study with the Cronbach's alpha of the variables of interest, multiple item scales, and factor analysis to reduce measurement 
error and increase construct validity. The second limitation is that excluding the recipients of small grants (i.e., those below €2000) from the sample may generate selection bias and distort the qualitative conclusions. Third, caution should be exercised in extending our findings to the entire population of grantees owing to the limited response rate achieved by the survey (20\%), which makes our sample representative of only $30 \%$ of the total FOB population. Finally, we do not intend to claim a direct causal link between business-like practices and organizational capacity but do acknowledge that reverse causality may represent a source of endogeneity in our study. For instance, it might be that a FOB decides to provide more nonfinancial support to a grantee once the latter has achieved a certain level of organizational capacity. Additional research should move in this direction. Notwithstanding its limitations, this study is one of the first attempts to map the relational dynamics between grantor and grantee and provides empirical support to what has been theorized by the literature over the past decade.

Future work could gather the perceptions of other players involved in the grantmaking process and whose opinion is often neglected. For instance, the perceptions of foundation employees who work hand-in-hand with the grantees could be analyzed to determine whether they are optimistic about the capacity-building processes of their foundation. Moreover, comparing development and performance data across accepted and rejected grant applicants may provide further intriguing insights. Finally, extending the analysis to the grantees of other foundations (e.g., foundations of corporate origin) as well as beyond Italy could allow for a comparison across different organizational settings and contexts and a critical evaluation of different relational models.

\section{Appendix 1: Survey questions used as variables}

\section{Resources and management capacity}

Did the relationship with the granting foundations contribute to improving: ( 1 not at all -7 extremely)

The ability to find non-governmental sources of funding?

The ability to find governmental sources of funding?

The ability to develop a client data system?

The ability to develop a fundraising plan?

The ability to use a budget for effective allocation of resources?

The ability to develop systems for financial management?

The ability to manage volunteers effectively?

The ability to develop the staff leadership?

The ability to provide professional development to the staff?

Program development capacity

Did the relationship with the granting foundations contribute to improving: (1 not at all-7 extremely)

The ability to increase the number of clients served?

The ability to extend services to new clients or communities?

The ability to increase the scope of services provided? 


\section{Support}

To what extent did your relationship with the foundation involve the following aspects? (1 not at all-7 extremely)

The foundation provides insights and advice about our field

The foundation provides advice on strategic and financial planning

The foundation provides support in the development of performance measures

The foundation introduces us to leaders in our field

The foundation provides advice on marketing and communication

The foundation provides advice on fundraising

Goal alignment

To what extent did your relationship with the foundation involve the following aspects? (1 not at all-7 extremely)

The objectives of our organization are aligned with those of the foundation

Our organization and the foundation are enthusiastic about pursuing the same objectives

Our organization and the foundation share the same vision on most of the issues to tackle

Oversight

To what extent did your relationship with the foundation involve the following aspects? (1 not at all—7 extremely)

The foundation emphasizes results and ideas for public dissemination

The foundation identifies the issues to tackle

The foundation specifies activities to undertake

The foundation identifies other organization to work with

The foundation evaluates the results of the project financed

Competitive selection

Did your organization participate in a competitive bid to obtain the grant? (1 yes; 0 no)

Multi-year project

What is the time horizon of the project financed with the grant? ( 1 more than one year; 0 up to one year)

\section{Appendix 2: Definition of variables}

\begin{tabular}{|c|c|}
\hline Variable & Definition \\
\hline Resources and management capacity & $\begin{array}{l}\text { Mean score of } 9 \text { items as reported in Appendix 1, rated on a } \\
\text { seven-point Likert scale }\end{array}$ \\
\hline Program development capacity & $\begin{array}{l}\text { Mean score of } 3 \text { items as reported in Appendix 1, rated on a } \\
\text { seven-point Likert scale }\end{array}$ \\
\hline Support & $\begin{array}{l}\text { Mean score of } 6 \text { items as reported in Appendix 1, rated on a } \\
\text { seven-point Likert scale }\end{array}$ \\
\hline Goal alignment & $\begin{array}{l}\text { Mean score of } 3 \text { items as reported in Appendix 1, rated on a } \\
\text { seven-point Likert scale }\end{array}$ \\
\hline Oversight & $\begin{array}{l}\text { Mean score of } 5 \text { items as reported in Appendix 1, rated on a } \\
\text { seven-point Likert scale }\end{array}$ \\
\hline Competitive selection & $\begin{array}{l}\text { Indicator variable equal to " } 1 \text { " if the grantee was selected through } \\
\text { a competitive bid; " } 0 \text { " otherwise }\end{array}$ \\
\hline
\end{tabular}




\begin{tabular}{|c|c|}
\hline Variable & Definition \\
\hline Multi-year project & $\begin{array}{l}\text { Indicator variable equal to " } 1 \text { " if the project financed with the } \\
\text { grant has a length of more than one year; " } 0 \text { " otherwise }\end{array}$ \\
\hline Grant amount & Natural logarithm of the grant amount received \\
\hline Association & $\begin{array}{l}\text { Indicator variable equal to " } 1 \text { " if the chair of the organization } \\
\text { surveyed is a nonprofit association; " } 0 \text { " otherwise }\end{array}$ \\
\hline Social cooperative & $\begin{array}{l}\text { Indicator variable equal to " } 1 \text { " if the chair of the organization } \\
\text { surveyed is a social cooperative; " } 0 \text { " otherwise }\end{array}$ \\
\hline Mature organization & $\begin{array}{l}\text { Indicator variable equal to " } 1 \text { " if the organization has existed for } \\
\text { more than } 10 \text { years; " } 0 \text { " otherwise }\end{array}$ \\
\hline Size & $\begin{array}{l}\text { Categorical variable equal to " } 0 \text { " if revenues realized by the } \\
\text { organization are equal to or below } € 50.000 \text {, " } 1 \text { " if revenues are } \\
\text { between } € 50.001 \text { and } € 100.000, \text { " } 2 \text { " if revenues are between } \\
€ 100.001 \text { and } € 500.000 \text {, and " } 3 \text { " if revenues are above } € 500.001\end{array}$ \\
\hline
\end{tabular}

Acknowledgements The authors acknowledge the financial support of the University of Padova, Projects CPDA158434; SIDBIRD2019, \& FSE 2014-2020, Veneto Region, Projects 4285-1-1267-2017. We are indebted to the Foundation of Banking Origin National Association, ACRI, for their help.

Funding Not Applicable.

Data availability Not applicable.

Code availability Proprietary dataset available on request.

\section{Declarations}

Conflict of interest The authors declared that they have no conflict of interest.

Open Access This article is licensed under a Creative Commons Attribution 4.0 International License, which permits use, sharing, adaptation, distribution and reproduction in any medium or format, as long as you give appropriate credit to the original author(s) and the source, provide a link to the Creative Commons licence, and indicate if changes were made. The images or other third party material in this article are included in the article's Creative Commons licence, unless indicated otherwise in a credit line to the material. If material is not included in the article's Creative Commons licence and your intended use is not permitted by statutory regulation or exceeds the permitted use, you will need to obtain permission directly from the copyright holder. To view a copy of this licence, visit http://creativecommons.org/licen ses/by/4.0/.

\section{References}

ACRI. (2018). XXIII Rapporto sulle Fondazioni di origine bancaria. ACRI.

Agyemang, G., O’Dwyer, B., Unerman, J., \& Awumbila, M. (2017). Seeking 'conversations for accountability': Mediating the impact of non-governmental organization (NGO) upward accountability processes. Accounting, Auditing and Accountability Journal, 30(5), 1-30.

Alexius, S., \& Grossi, G. (2018). Decoupling in the age of market-embedded morality: Responsible gambling in a hybrid organization. Journal of Management and Governance, 22(2), 285-313.

Alman, I. (2016). Half of Nonprofits are set up to fail-How about your favorite? Forbes. Retrieved January 21, 2021, from https://www.forbes.com/sites/ianaltman/2016/03/20/half-of-nonprofits-aresetup-to-fail-how-about-your-favorite/?sh=74efd2f64619 
Anheier, H. K. (2005). Nonprofit organisations: Theory, management, policy. Routledge.

Austin, M. J., Regan, K., Samples, M. W., Schwartz, S. L., \& Carnochan, S. (2011). Building managerial and organizational capacity in nonprofit human service organizations through a leadership development program. Administration in Social Work, 35(3), 258-281.

Awio, G., Northcott, D., \& Lawrence, S. (2011). Social capital and accountability in grass-roots NGOs: The case of the Ugandan community-led HIV/AIDS initiative. Accounting, Auditing and Accountability Journal, 24(1), 63-92.

Bailin, M. A. (2003). Re-engineering philanthropy: Field notes from the trenches. Edna McConnell Clark Foundation.

Benjamin, L. M. (2020). Bringing beneficiaries more central into nonprofit management education and research. Nonprofit and Voluntary Sector Quarterly, 50(1), 1-22.

Bish, A., \& Becker, K. (2015). Exploring expectations of nonprofit management capabilities. Nonprofit and Voluntary Sector Quarterly, 45(3), 437-457.

Boesso, G., \& Cerbioni, F. (2019). Governance and strategic philanthropy in grant-making foundations: How to improve the effectiveness of nonprofit boards. Palgrave Macmillan.

Boesso, G., Cerbioni, F., Menini, A., \& Parbonetti, A. (2017). The role of the board in shaping foundations' strategy: An empirical study. Journal of Management and Governance, 21(2), 375-397.

Caers, R., Du Bois, C., Jegers, M., De Gieter, S., Schepers, C., \& Pepermans, R. (2006). Principal-agent relationships on the stewardship-agency axis. Nonprofit Management \& Leadership, 17(1), $25-47$.

Centre for Effective Philanthropy. (2008). More than money: Making a difference with assistance beyond the grant. Centre for Effective Philanthropy.

Centre for Effective Philanthropy. (2017). Relationships matter. Program officers, grantees and the key to success. Centre for Effective Philanthropy.

Chapman, C. L., \& Varda, D. M. (2017). Nonprofit resource contribution and mission alignment in interorganizational, cross-sector public health networks. Nonprofit and Voluntary Sector Quarterly, 46(5), 1052-1072.

Clerkin, M., \& Quinn, A. (2019). Restricted funding: Restricting development? VOLUNTAS: International Journal of Voluntary and Nonprofit Organizations, 30, 1348-1364.

Cornforth, C., \& Mordaunt, J. (2011). Organisational capacity building: Understanding the dilemmas for foundations of intervening in small and medium-size charities. VOLUNTAS: International Journal of Voluntary and Nonprofit Organizations, 22(3), 428-449.

Coupet, J., \& Berrett, J. L. (2019). Toward a valid approach to nonprofit efficiency measurement. Nonprofit Management \& Leadership, 29(3), 299-320.

de Azevedo, S. U., \& Braga de Aguiar, A. (2020). Paying enough but not paying too much when there is no third-party endorsement: Executive compensation and individual donations for nonprofit organizations. VOLUNTAS: International Journal of Voluntary and Nonprofit Organizations. https://doi. org/10.1007/s11266-020-00225-6

De Clercq, D., \& Sapienza, H. J. (2006). Effects of relational capital and commitment on venture capitalists' perception of portfolio company performance. Journal of Business Venturing, 21(3), 326-347.

Dekker, H. C. (2004). Control of inter-organizational relationships: Evidence on appropriation concerns and coordination requirements. Accounting, Organizations and Society, 29, 27-49.

Delfin, F. G., Jr., \& Tang, S. Y. (2008). Foundation impact on environmental nongovernmental organizations: The grantees' perspective. Nonprofit and Voluntary Sector Quarterly, 37(4), 603-625.

Despard, M. R. (2017). Can nonprofit capacity be measured? Nonprofit and Voluntary Sector Quarterly, 46(3), 607-626.

Dhanani, A., \& Connolly, C. (2015). Non-governmental organizational accountability: Talking the talk and walking the walk? Journal of Business Ethics, 29(1), 613-637.

Ebarb, T. (2019). Nonprofits fail-Here's seven reasons why. National Association of Nonprofit Organizations \& Executives (NANOE). Retrieved January 21, 2021, from https://nanoe.org/nonprofits-fail/

Fairfield, K. D., \& Wing, K. T. (2008). Collaboration in foundation grantor-grantee relationships. Nonprofit Management and Leadership, 19(1), 27-44.

Fisher, J. (1995). Contingency-based research in management control systems: Categorization by level of complexity. Journal of Accounting Literature, 14, 24-53.

Global Philanthropy Report. (2018). Perspective on the global foundation sector. Harvard Kennedy School.

Hair, J. F., Anderson, R. E., Tatham, R. L., \& Black, W. C. (1995). Multivariate data analysis (3rd ed.). Macmillan Publishing Company. 
Haugen, R. A., \& Senbet, L. W. (1981). Resolving the agency problems of external capital through options. The Journal of Finance, 36(3), 629-647.

Herrold, C. (2006). High-engagement philanthropy: The grantee's perspective. Voluntary Sector Working Paper, 4.

Hinna, A., \& Monteduro, F. (2017). Boards, governance and value creation in grant-giving foundations. Journal of Management and Governance, 21(4), 935-961.

Hume, J., \& Leonard, A. (2014). Exploring the strategic potential of internal communication in international non-governmental organisations. Public Relations Review, 40(2), 294-304.

Jariego, I. M., Holgado, D., Tinoco, E. G., Alvis, A. M., \& Gil, M. O. (2020). More money, more problems? Resource dependence and professionalization of non-governmental social services organizations in southern Spain. VOLUNTAS International Journal of Voluntary and Nonprofit Organizations, 31, 1212-1225.

Laurett, R., \& Ferreira, J. J. (2018). Strategy in nonprofit organisations: A systematic literature review and agenda for future research. VOLUNTAS: International Journal of Voluntary and Nonprofit Organizations, 29(5), 881-897.

Leardini, C., Moggi, S., \& Rossi, G. (2019). The new era of stakeholder engagement: Gaining, maintaining, and repairing legitimacy in nonprofit organizations. International Journal of Public Administration, 42(6), 520-532.

Leardini, C., Rossi, G., Moggi, S., \& Zardini, A. (2017). When the law shapes nonprofit boards: The key role of local stakeholders. Nonprofit and Voluntary Sector Quarterly, 46(1), 47-70.

Letts, C. W., Ryan, W., \& Grossman, A. (1997). Virtuous capital: What foundations can learn from venture capitalists. Harvard Business Review, 75(2), 36-44.

Lu, J., Shon, J., \& Zhang, P. (2020). Understanding the dissolution of nonprofit organizations: A financial management perspective. Nonprofit and Voluntary Sector Quarterly, 49(1), 29-52.

Ma, J., \& Konrath, S. (2018). A century of nonprofit studies: Scaling the knowledge of the field. VOLUNTAS: International Journal of Voluntary and Nonprofit Organizations, 29(6), 1139-1158.

MacIndoe, H., \& Sullivan, F. (2014). Nonprofit response to financial uncertainty: How does financial vulnerability shape nonprofit collaboration. Journal of Management \& Sustainability, 4(3), 1-15.

Maier, F., Meyer, M., \& Steinbereithner, M. (2016). Nonprofit organizations becoming business-like: A systematic review. Nonprofit and Voluntary Sector Quarterly, 45(1), 64-86.

McMullin, C., \& Raggo, P. (2020). Leadership and governance in times of crisis: A balancing act for nonprofit boards. Nonprofit and Voluntary Sector Quarterly, 49(6), 1182-1190.

Minà, A., Dagnino, G. B., \& Vagnani, G. (2020). An interpretive framework of the interplay of competition and cooperation. Journal of Management and Governance, 24(1), 1-35.

Moody, M. (2008). Building a culture: The construction and evolution of venture philanthropy as a new organizational field. Nonprofit and Voluntary Sector Quarterly, 37(2), 324-352.

Ostrower, F. (2004). Attitudes and practices concerning effective philanthropy: Survey report. Retrieved June 1, 2021, from http://webarchive.urban.org/UploadedPDF/411067_attitudes_practices_FR.pdf

Peng, S., Kim, M., \& Deat, F. (2019). The effects of nonprofit reputation on charitable giving: A survey experiment. VOLUNTAS: International Journal of Voluntary and Nonprofit Organizations, 30, 811-827.

Porter, M. E., \& Kramer, M. R. (1999). Philanthropy's new agenda: Creating value. Harvard Business Review, 77, 121-131.

Qu, H., \& Daniel, J. L. (2020). Is “overhead" a tainted word? A survey experiment exploring framing effects of nonprofit overhead donor decision. Nonprofit and Voluntary Sector Quarterly. https://doi. org/10.1177/0899764020959475

Rey-García, M., Calvo, N., \& Mato-Santiso, V. (2019). Collective social enterprises for social innovation. Management Decision, 57(6), 1415-1440.

Ricciuti, E., \& Swierczynska, U. (2018). Powering social innovations-the role of Italian foundations in facilitating social innovation. The grantees' perspective. CRC Working Paper, N. 22.

Rogers, R. (2015). Why the social sciences should take philanthropy seriously. Society, 52(6), 533-540.

Sanders, M. L., \& McClellan, J. G. (2014). Being business-like while pursuing a social mission: Acknowledging the inherent tensions in US nonprofit organizing. Organization, 21(1), 68-89.

Sen, A. (2013). The ends and means of sustainability. Journal of Human Development and Capabilities, 14(1), 6-20.

Suykens, F., De Rynck, B., \& Verschuere, A. (2020). Examining the extent and coherence of nonprofit hybridization toward the market in a post-corporatist welfare state. Nonprofit and Voluntary Sector Quarterly, 49(5), 909-930. 
Van Puyvelde, S., Caers, R., Du Bois, C., \& Jegers, M. (2012). The governance of nonprofit organizations: Integrating agency theory with stakeholder and stewardship theories. Nonprofit and Voluntary Sector Quarterly, 41(3), 431-451.

Vangen, S., \& Huxham, C. (2003). Nurturing Collaborative relationships: Building trust in interorganizational collaborations. Journal of Applied Behavioral Science, 39(1), 5-31.

Publisher's Note Springer Nature remains neutral with regard to jurisdictional claims in published maps and institutional affiliations.

Giacomo Boesso is Professor of Business Administration at the University of Padova (Italy). His research interests cover nonprofit governance, corporate sustainability and stakeholder management.

Fabrizio Cerbioni is Professor of Accounting at the University of Padova (Italy). His research interests cover profit and nonprofit governance, performance management and accounting history.

Andrea Menini is Associate Professor of Accounting at the University of Padova (Italy). His research interests cover financial accounting, nonprofit governance and risk management.

Giulia Redigolo is Assistant Professor of Accounting at ESADE Business School, University Ramon Llull, Barcelona (Spain). Her research interests cover financial archival with an emphasis on corporate disclosure decisions, capital markets as well as corporate governance and the non-profit sector. 